\title{
Analysis of Carbon Flux in Terrestrial Ecosystems from GOSAT Data in China
}

\author{
Lanlan Zhang ${ }^{1,2}$, Jinye Zhang ${ }^{1,2, *}$, Hui Lv ${ }^{1}$, Bangwu Sun ${ }^{1}$ \\ ${ }^{1}$ School of Science, Hubei University of Technology, Wuhan 430068; \\ ${ }^{2}$ Hubei Collaborative Innovation Ceter for High-efficiency Utilization of Solar Energy, Hubei University of Technology, Wuhan 430068;
}

\begin{abstract}
In recent years, the evaluation of carbon sources and carbon sinks has become one of the major research topics. The temporal and spatial distribution of carbon flux and some factors that affect carbon flux were analyzed in this paper based on the Net Ecosystem Exchange (NEE) data, which were provided by Greenhouse Gases Observing Satellite (GOSAT) project and FLUXNET project. Then, we found that carbon flux had obvious seasonal variation. It was carbon sink in summer and carbon source in winter. The total amount of carbon flux in July or August was about -1.377 -1.882 gcm-2day-1, and 0.64 gcm-2day-1 in November. The fluctuation of carbon flux in coastal area was stronger than that in inland. Forest areas had stronger carbon storage capacity than that in other vegetation areas, and the flux in forest areas had the largest change. The vegetation coverage was larger, and the carbon storage capacity was stronger.
\end{abstract}

\section{Introduction}

Since the industrial revolution, human's emissions $(\mathrm{CO} 2$, $\mathrm{CH} 4$, etc.) increased significantly owing to economic and population growth. Greenhouse gas was one of the main causes of global warming. The fifth assessment report of the Intergovernmental Panel on Climate Change (IPCC) showed that climate change was a devastating impact on the continental and marine ecosystems ([1]). Since 1950, the influence of the global carbon cycle on extreme weather such as heavy rainfall has become an important international issue.

At present, there are some observation networks to obtain carbon flux about terrestrial ecosystem. In 1997, the FLUXNET was established with more than 500 tower sites around the world. The eddy covariance methods were used to measure the exchanges of carbon dioxide, water vapor, and energy between terrestrial ecosystems and the atmosphere. However, the carbon flux was highly uncertain about future climate predictions because of the scarcity of observation sites ([2,3]). Remote sensing is an effective way to obtain large scale, stable, and continuous carbon fluxes. Japan launched the GOSAT on January 23 in 2009. GOSAT project released standard data products from L1 to L4 gradually through continuous adjustment, calibration and verification. The L4A data products are monthly fluxes of $\mathrm{CO} 2$ and $\mathrm{CH} 4$ estimated for sub-continental regions. These fluxes are obtained from the XCO2 and XCH4. Kadygrov et al. ([4]) concluded that it was possible to reduce the mean regional flux uncertainty by approximately $30 \%$ through adding satellite observations with $2.5 \mathrm{ppm}$ single-shot random error and a bias of $1 \mathrm{ppm}$. Basu et al. ([5]) reached that small spatio-temporal biases had serious consequences for optimized fluxes.

Terrestrial ecosystems are diverse in China. There are forest ecosystems, grassland ecosystems, desert ecosystems, wetland ecosystems, and farmland ecosystems with human intervention. China is a natural laboratory for studying terrestrial ecosystem carbon revenues, carbon cycles and its global changes. China is an important area that has a significant impact on global climate change. Li Zhang et al. ([6]) obtained that the consumption of fossil fuels in China leads to carbon dioxide emissions of $1.90 \mathrm{PgC} \mathrm{a}^{-1}$ into the atmosphere. Therefore, it is important to study the temporal and spatial distribution of carbon sources and carbon sinks in China.

\section{Analysis of Carbon Flux in China}

\subsection{Validation of GOSAT Data}

The tower site data of $\mathrm{CN}-\mathrm{Cng}$ and $\mathrm{CN}-\mathrm{SW} 2$ were obtained through FLUXNET. Some introductions of them were showed in Table 1.

Table 1. Introduction of CN-Cng and CN-SW2

\begin{tabular}{|c|c|c|c|c|}
\hline $\begin{array}{c}\text { Site } \\
\text { ID }\end{array}$ & Site Name & $\begin{array}{c}\text { Latitude } \\
\left({ }^{\circ}\right)\end{array}$ & $\begin{array}{c}\text { Longitude } \\
\left({ }^{\circ}\right)\end{array}$ & IGBP \\
\hline CN- & $\begin{array}{c}\text { Chang-lin } \\
\text { Cng }\end{array}$ & 44.59 & 123.51 & Grassland \\
\hline $\begin{array}{c}\text { CN-S } \\
\text { W2 }\end{array}$ & $\begin{array}{c}\text { Siziwang } \\
\text { Grazed }\end{array}$ & 41.79 & 111.90 & Grassland \\
\hline
\end{tabular}

In Fig. 1 and table 2, a validation analysis of GOSAT L4 data and tower site data in 2010 was showed.

\footnotetext{
* Corresponding author:zhangjinye@hbut.edu.cn
} 
They had good consistency, and $\mathrm{R}^{2}$ were 0.823 ( $\mathrm{CN}-\mathrm{Cng}$ ) and 0.574 (CN-SW2).

$\mathrm{NEE}_{\mathrm{GOSAT}}$ data and $\mathrm{NEE}_{\mathrm{GROUND}}$ data had obvious seasonal variation. Carbon source is positive, and carbon sink is negative. In summer, photosynthesis of plants was stronger, and carbon emissions was less than carbon absorption. The situation in winter was opposite in summer. Therefore, carbon flux was carbon sink in summer and carbon source in winter. In spring and autumn, photosynthesis of plants was weaker, it was light carbon sink or carbon source.

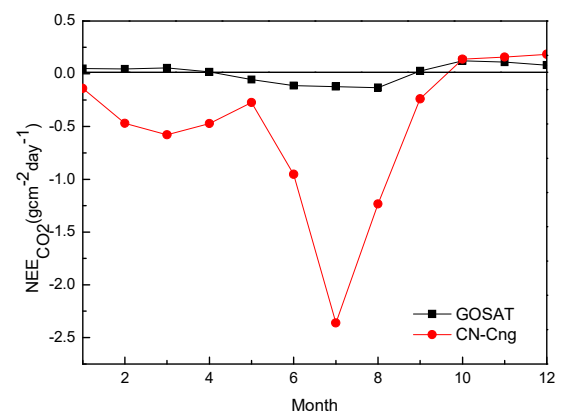

(a) Comparison of CN-Cng site data with GOSAT data

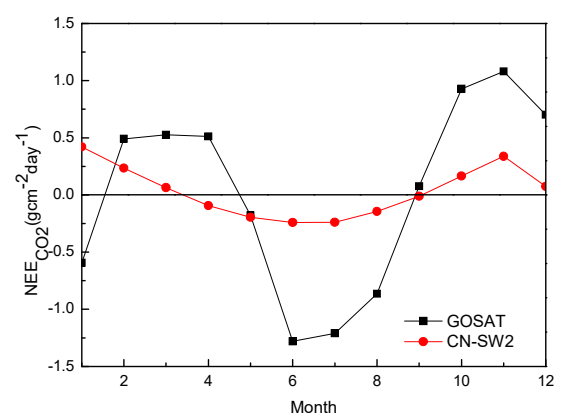

(b) Comparison of CN-SW2 site data with GOSAT data

Fig. 1. Carbon flux from tower site data and GOSAT data in 2010

However, the value of carbon flux was biased. The reasons were as follows: (1) They had different spatial measurement scales. (2) GOSAT data was uncertain. It is important to improve the accuracy of carbon flux by analysing the uncertainty of GOSAT data.

Table 2. Comparison of tower site data with GOSAT data

\begin{tabular}{|c|c|c|c|c|c|}
\hline & \multicolumn{2}{|c|}{$\begin{array}{c}\text { Average value } \\
\left(\mathrm{gcm}^{-2} \text { day }^{-1}\right)\end{array}$} & \multicolumn{2}{c|}{$\begin{array}{c}\text { Standard } \\
\text { deviation }\end{array}$} & \multirow{2}{*}{$\mathrm{R}^{2}$} \\
\cline { 2 - 5 } & site & GOSAT & site & GOSAT & \\
\hline $\begin{array}{c}\text { CN-C } \\
\text { ng }\end{array}$ & -0.52 & 0.72 & 5.11 & 0.09 & $0.823^{* *}$ \\
\hline $\begin{array}{c}\text { CN-S } \\
\text { W2 }\end{array}$ & 0.031 & 0.015 & 0.22 & 0.83 & 0.574 \\
\hline
\end{tabular}

**. Correlation is significant at the 0.01 level

\subsection{Spatial and Temporal Distribution}

GOSAT L4A products are carbon fluxes. There are imposed surface $\mathrm{CO}_{2}$ flux due to fossil fuel burning, biomass burning, terrestrial biosphere exchange and air-sea exchange respectively. The carbon fluxes that were produced by the air-sea exchange were much

smaller than that produced by other factors, its impact on the spatio-temporal distribution of carbon flux in China could be neglected in this paper. Therefore,

$$
N E E_{\text {bio }}=N E E_{\text {opt }}-N E E_{b m b}-N E E_{\text {fsl }}
$$

$N E E_{b i o}, N E E_{b m b}$ and $N E E_{f s l}$ were carbon flux that produced by terrestrial biosphere exchange, biomass burning, fossil fuel burning, respectively. $N E E_{o p t}$ was optimized surface carbon flux.

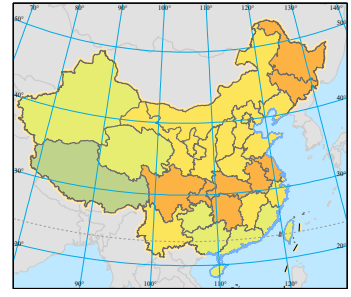

(a) Jan

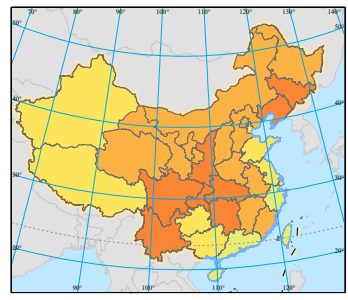

(c) Mar

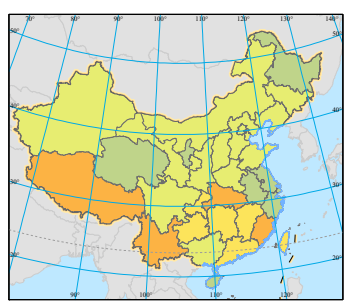

(e) May

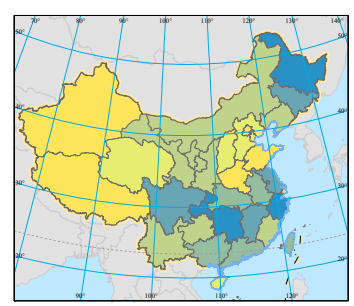

(g) Jul

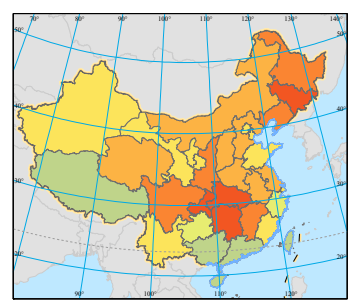

(i) Sept

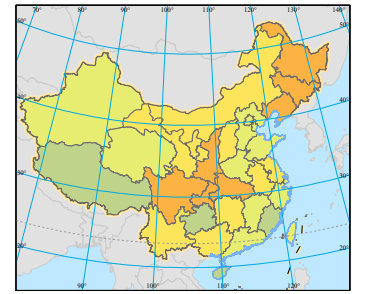

(b) Feb

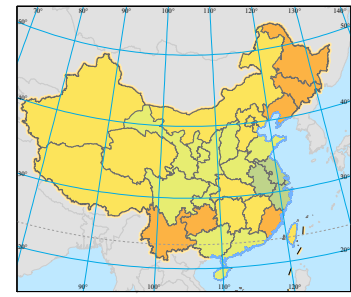

(d) Apr

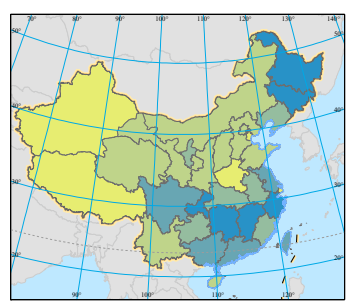

(f) Jun

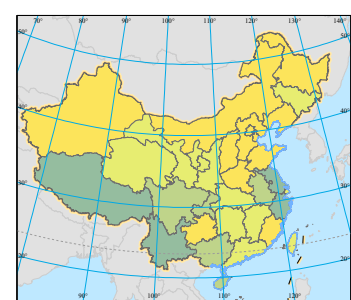

(h) Aug

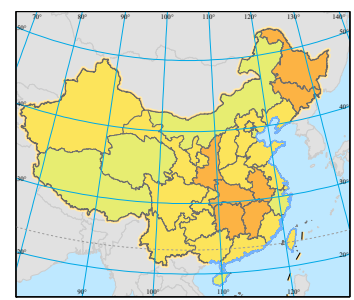

(j) Oct 


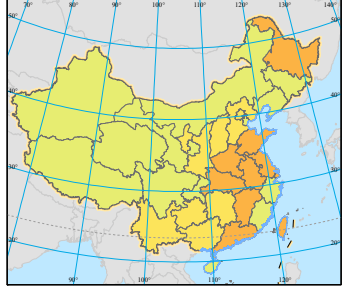

(k) Nov

$\begin{array}{llllllllll}-4 & -3.2 & -2.4 & -1.6 & -0.8 & 0 & 0.8 & 1.6 & 2.4 & 3.2\end{array}$

Fig. 2. Temporal and spatial distribution of monthly carbon flux in 2014 in China

Fig. 2. showed the temporal and spatial distribution of carbon flux from January 2014 to December 2014 in China. It could be founded that the change of carbon flux had obvious seasonal variation and regional distribution. It was carbon sink in summer and carbon source in winter, which was consistent with the conclusion of Fig. 1. The total amount of carbon flux was about $-1.377 \sim$ -1.882 gcm-2day-1 in July or August and 0.64 gcm-2day-1 in November. The fluctuation of carbon flux in coastal area was stronger than that in inland.

In summer, the eastern was strong carbon sinks, and the western region was light carbon sinks or carbon sources. In July, carbon flux was $-3.2460 \mathrm{gcm}-2$ day-1 in Heilongjiang and $0.0217 \mathrm{gcm}-2$ day-1 in Tibet Autonomous Region. In winter, the western were light carbon sinks, while most parts of the eastern were carbon sources. In November, it was $-0.459 \mathrm{gcm}-2$ day- 1 in Tibet Autonomous Region and $2.471 \mathrm{gcm}-2$ day-1 in Hubei province. This was closely related to vegetation growth cycle, vegetation distribution, and vegetation coverage.

\subsection{Comparison of carbon flux in different vegetation areas}

NEEGOSAT data is affected by vegetation type, vegetation coverage, climate and so on. The effect of various factors on carbon flux was analyzed in this paragraph.

The distribution of vegetation in China can be divided into eight type: cold temperate deciduous coniferous forest area (A1), the temperate coniferous broad-leaved mixed forest (A2), the warm temperate deciduous broad-leaved forest (A3), the subtropical evergreen broad - leaved forest area (A4), tropical rainforest area (A5), temperate grassland area (A6), temperate desert area (A7) and Qinghai - Tibet Plateau alpine vegetation area (A8). It can be seen from Fig. 3 that the seasonal variation of carbon flux in different vegetation areas was consistent.

Table3. Vegetation type and carbon flux in different province

\begin{tabular}{|c|c|c|c|c|c|}
\hline & Hubei & $\begin{array}{c}\text { Zhe-jian } \\
\mathrm{g}\end{array}$ & $\begin{array}{c}\text { Inner-Mongo } \\
\text { lia }\end{array}$ & $\begin{array}{c}\text { Heilong-ji } \\
\text { ang }\end{array}$ & $\begin{array}{c}\text { Sin- } \\
\text { kiang }\end{array}$ \\
\hline type & $\mathrm{A} 4$ & $\mathrm{~A} 4$ & $\mathrm{~A} 6$ & $\mathrm{~A} 2$ & $\mathrm{~A} 7$ \\
\hline $\begin{array}{c}\text { forest } \\
\left(\mathrm{m}^{2} \times 10^{8}\right)\end{array}$ & 713.8 & 601.4 & 2487.9 & 1962 & 698.2 \\
\hline $\begin{array}{c}\text { coverage } \\
(\%)\end{array}$ & 38.4 & 59.1 & 21.1 & 43.2 & 4.24 \\
\hline carbon flux & 0.33 & -0.93 & -0.11 & -0.22 & -0.05 \\
\hline
\end{tabular}

Table 3 showed that the vegetation types and carbon flux in different province. Hubei and Zhejiang are located in A4, but vegetation coverage in Zhejiang was larger than that in Hubei. The vegetation coverage was same in Heilongjiang and Inner Mongolia, but there are located in different vegetation area. The effect of vegetation coverage and vegetation type could be analyzed in this paragraph. The forest area, vegetation coverage and grassland area were obtained from the "China Statistical Yearbook". Carbon flux data were provided by GOSAT project.

Fig. 3. showed that the comparison of carbon flux in different provinces. It could be concluded that the seasonal variation of carbon flux in different provinces was same, which was consistent with the result in Fig. 2.

In Fig. 3. (a), Zhejiang was carbon sink from March to October, and Hubei was carbon sink from June to September. The total amount of carbon flux was -0.925 gcm-2day-1 (Zhejiang) and 0.329 gcm-2day-1 (Hubei). Zhejiang was carbon sink, while Hubei was carbon source. Although they are located in A4, vegetation coverage in Zhejiang was larger and the plants can absorb more $\mathrm{CO} 2$ through photosynthesis.

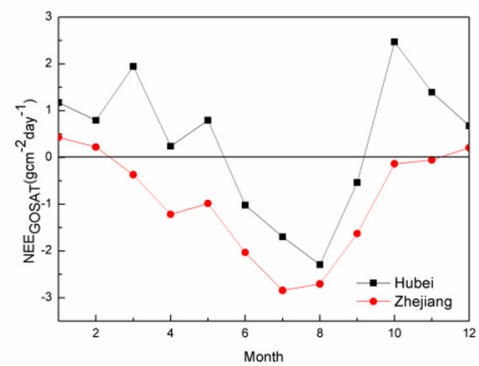

(a) Comparison of Hubei with Zhejiang

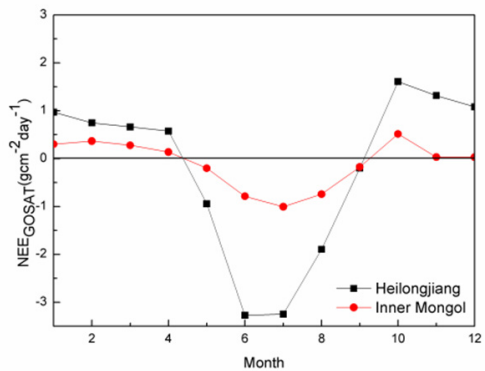

(b) Comparison of Heilongjiang with Inner Mongol

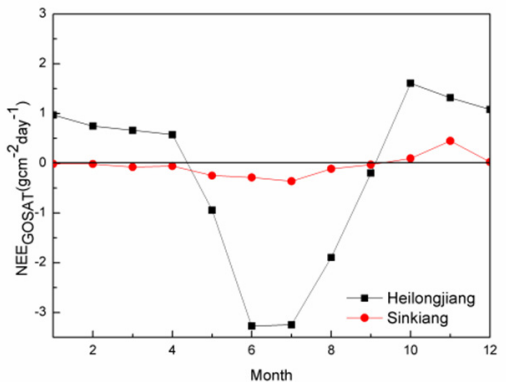

(c) Comparison of Heilongjiang with Sinkiang

Fig. 3. Comparison of NEEGOSAT data in different province in 2014 
In Fig. 3 (b), Heilongjiang and Inner Mongolia were carbon sink from May to September. The total amount of carbon flux were $-0.2156 \mathrm{gcm}-2$ day-1 (Heilongjiang) and -0.104 gcm-2day-1 (Inner Mongolia). Heilongjiang is located in A1 and A2, while Inner Mongolia is located in A6. Therefore, forest areas had stronger carbon sink capacity than that in grassland areas. Schwartz et al. ([7]) also concluded that the forest had the strongest carbon sink capacity. They were carbon source in other months because of the weaker photosynthesis of plants. The amount of carbon source in Heilongjiang was larger than that in Inner Mongolia, because carbon dioxide was much more produced by autoxidation of the forest.

In Fig. 3 (b). and Fig. 3 (c), the carbon flux had not changed too much in Xinjiang and Inner Mongolia, and the balance of carbon budget was maintained. The change of carbon flux in Heilongjiang was larger, which also verified that the change of carbon flux in forest areas was much larger.

\section{Conclusion}

Through the verification, comparison and analysis of $\mathrm{NEE}_{\mathrm{GOSAT}}$ and $\mathrm{NEE}_{\mathrm{GROUNG}}$, we could get the following conclusions:

$\mathrm{NEE}_{\mathrm{GOSAT}}$ and $\mathrm{NEE}_{\mathrm{GROUNG}}$ had good consistency, and $\mathrm{R}^{2}$ were $0.823(\mathrm{CN}-\mathrm{Cng})$ and $0.574(\mathrm{CN}-\mathrm{SW} 2)$.

The carbon flux had obvious seasonal variation and temporal distribution in China. It was carbon sink in summer and carbon source in winter. In summer, the eastern was strong carbon sinks, and the western was weak carbon sinks or carbon sources. In winter, the western was weak carbon sinks, while most parts of the eastern was carbon sources. The fluctuation of carbon flux in coastal area was stronger than that in inland.

The carbon flux was closely related to vegetation growth cycle, vegetation distribution, vegetation coverage and so on. When located in the same vegetation area, forest coverage had a significant impact on carbon flux. When vegetation coverage was same, forest areas showed stronger carbon sinks and had stronger carbon sink capacity. The carbon flux had not changed too much in grassland areas and the balance of carbon budget was maintained.

\section{Acknowledgment}

The authors are grateful for the carbon flux data provided by GOSAT project and the tower site data provided by FLUXNET project. This project was supported by the funds from the Hubei Collaborative Innovation Center for High-efficiency Utilization of Solar Energy, Hubei University of Technology (HBSKFZD2016002, HBSDY201502) and Undergraduate Training Program for Innovation and Entrepreneurship (201510500058).

\section{References}

1. Intergovernmental Panel on Climate Change (IPCC). 2013
2. Buchwitz, M., Schneising, O., Burrows, J. P., Bovensmann, H., Reuter, M., and Notholt, J. First direct observation of the atmospheric $\mathrm{CO}_{2}$ year-to-year increase from space. Atmospheric Chemistry and Physics. 7: 4249-4256 (2007).

3. He, Q., Yu, T., Chen T., Gu X., Xie D., and Wu Y. Atmospheric Carbon Dioxide Satellite Remote Sensing Retrieval Accuracy Inspection and Spatiotemporal Characteristics Analysis. Journal of Geo-Information Science. (02): 250-257 (2012).

4. Kadygrov, N., S. Maksyutov, N. Eguchi, T. Aoki, T. Nakazawa, T. Yokota, G.Inoue, Role of simulated GOSAT total column $\mathrm{CO}_{2}$ observations in surface $\mathrm{CO}_{2}$ flux uncertainty reduction, Journal of Geophysical Research: Atmospheres. 114, D21208, (2009).

5. Basu, S., Guerlet, S., Butz, A., Houweling, S., Hasekamp, O., Aben, I., Krummel, P., Steele, P., Langenfelds, R., Torn, M., Biraud, S., Stephens, B., Andrews, A., and Worthy, D. Global CO2 fluxes estimated from GOSAT retrievals of total column $\mathrm{CO}_{2}$. Atmospheric Chemistry and Physics. 13(17): 8695-8717(2013).

6. Zhang, L., Xiao, J., Li, L., Lei, L., and Li, J. China's sizeable and uncertain carbon sink: a perspective from GOSAT. Chinese Science Bulletin. 59(14): 1547-1555 (2014).

7. Schwartz, M. D., Hanes, J. M., and Liang, L. Comparing carbon flux and high-resolution spring phenological measurements in a northern mixed forest. Agricultural and Forest Meteorology, 169(169), 136-147 (2013). 